\title{
Upper gastro-intestinal bleeding: Aetiology and demographic profile based on endoscopic examination at Dhulikhel Hospital, Kathmandu University Hospital
}

\section{Gurung RB ${ }^{1}$, Joshi G ${ }^{2}$, Gautam N$^{2}$, Pant P1 ${ }^{1}$, Pokhrel B ${ }^{1}$, Koju R ${ }^{3}$, Bedi TRS ${ }^{4}$}

${ }^{1}$ Lecturer, ${ }^{2}$ Intern, ${ }^{3}$ Assistant Professor, ${ }^{4}$ Professor, Internal Medicine, Dhulikhel Hospital Kathmandu University School of Medical Science

\begin{abstract}
Background: The upper gastrointestinal bleeding (UGIB) is defined as bleeding within the intraluminal gastrointestinal tract from any location between the upper oesophagus to the duodenum at the ligament of Treitz. It is one of the important medical emergencies worldwide.

Objective: The objective of this study is to study the aetiology of upper gastrointestinal bleeding based on endoscopic examination findings in patients of various demographic characteristics.

Materials and methods: This is a retrospective observational study. The endoscopic record book from 2007 January to 2009 October was reviewed for all the cases who underwent oesophago-gastro-duodenoscopic examination for upper GI bleeding. The clinico-epidemiological data of all the patients was reviewed and analyzed in concert with the aetiology of bleeding.

Results: A total of 90 patients (58 males, 32 females; mean age $45.32 \pm 18.47$ years) of upper gastrointestinal bleeding was studied and analyzed in terms of aetiology of bleeding and demographic profile. Among the ethnic groups, Aryan $46(51 \%)$ was the most common ethnic group to have upper GI bleeding followed by Newars 24 (27\%), Mongolians 16 (18\%), Dalits $3(3 \%)$ and others 1 (1\%). Out of 90 patients, $47(52.2 \%)$ cases was less than 45 years of age, 30(33.3\%) of 46 to 65 age ; and 13(14.4\%) more than 65 years of age.

Gastric ulcer 23(25.6\%) was the most common endoscopic finding, followed by oesophageal varices 14 (15.6\%), acute erosive/haemorrhagic gastropathy $11(12.2 \%)$, duodenal ulcer 9(10\%), growth $7(7.8 \%)$, vascular lesions 3(3.3\%), Mallory-Weiss tear 1(1.1\%), fundal varices 1(1.1\%) and, no cause was identified in 21(23.3\%) cases.

The peptic ulcer bleeding was the most common finding in Aryan 22(47.9\%), whereas oesophageal varices and growth were more common in Newar 7(29.2\%) and $3(12.5 \%)$ respectively.

Conclusion: Peptic ulcer disease is the most common cause of upper GI bleeding which was most commonly found in Aryan population; followed by oesophageal varices and growth as second and third most common causes and were more prevalent in Newar and Mongolian people.
\end{abstract}

Key words: Endoscopy, Peptic ulcer disease, Upper GI bleeding, Varices

$\mathrm{T}$ he upper gastrointestinal bleeding (UGIB) is defined as bleeding within the intraluminal gastrointestinal tract from any location between the upper oesophagus to the duodenum at the ligament of Treitz. Bleeding from the gastrointestinal tract may present in five ways: 1) haematemesis, 2) malena, 3) haematochezia, 4) occult gastrointestinal bleeding, and 5) features of blood loss or anaemia such as light headedness, syncope, angina, or dyspnoea ${ }^{1}$.

Upper gastrointestinal bleeding is one of the important medical emergencies worldwide, accounting for high morbidity and mortality ${ }^{2,3}$. It is estimated that $1-2 \%$ of all acute admissions are due to GI bleeding ${ }^{4}$. More than 350,000 hospital admissions are attributable to upper gastrointestinal bleeding, which has an overall mortality rate of $10 \%$. Despite the fact that more than $75 \%$ of cases of bleeding ceases spontaneously and require only supportive measures, however, most of the patients require further intervention, which often involves the combined efforts of gastroenterologists, surgeons, and interventional radiologists ${ }^{5,6}$.

Correspondence

Dr. Ram Bahadur Gurung

Department of Internal Medicine

Dhulikhel Hospital, Kathmandu University Hospital

E-mail: ramgurung@hotmail.com 
Upper GI endoscopy is the most valuable initial procedure of choice for the evaluation of acute upper gastrointestinal bleeding. Early endoscopy allows not only the detection of cause and source of bleeding it also gives estimation of the risk of recurrent bleeding and potentially enables various therapeutic options. Studies have shown that early endoscopy is associated with lower healthcare costs and improved medical outcomes, compared with other procedures. However, upper GI endoscopic findings are nondiagnostic in about $10 \%$ of $\operatorname{cases}^{7,8,9,10}$.

There are very few published studies in upper GI bleeding particularly from the health institutions at urban areas. The study of upper GI bleeding at rural community settings in Nepal is scarce. Dhulikhel hospital which is also a University teaching hospital provides health services largely to the rural community population of a diverse ethnic backgrounds and cultural practices. The aim of this study was to study the aetiology of upper GI bleeding based on endoscopic examinations in relation with demographic characteristics of the patients.

\section{Materials and methods}

This is a retrospective study on patients of upper gastrointestinal bleeding who underwent oesophagogastroduodenoscopy in the period of January 2007 to October 2009. All clinico-epidemiological data was reviewed and analyzed. The inclusion criteria for the study were the presence of any one of the following: 1) haematemesis 2) malena or both 3) nasogastric aspirate of blood; and 4) recent onset anaemia with positive occult blood were taken as the clinical definition of upper GI bleeding. The patients with upper gastrointestinal bleeding but inadequate information on registry were excluded. The distributions of age, gender and ethnic background in the study sample were determined. The relative frequencies of different causes of UGI bleed in people of different ethnic groups were studied. Data management and statistical work up was performed by using software SPSS 13 version.

\section{Results}

A total of 108 cases of upper GI bleeding was identified through review of endoscopic register from January 2007 to October 2009. 18 cases were excluded due to inadequate information on the registry. The remaining 90 cases of upper GI bleeding was studied and analyzed in terms of aetiology of bleeding and demographic profile.

There were 58(64.4\%) males and $32(35.6 \%)$ females, and the male-female ratio was $1.8: 1$. The mean age of the population was $45.32+18.47$ years.

Among the ethnic groups, Aryan (51\%) was the most common group to have upper GI bleeding followed by Newars (27\%), Mongolians (18\%), Dalits (3\%) and others $(1 \%)$ respectively. Out of 90 cases, $52.2 \%$ of upper GI cases was of young age group (15 to 45 age) followed by $33.3 \%$ middle age group (46 to 65 age) ; and only $14.4 \%$ elderly group (> 65 age). (Table 1 )

With regard to aetiology of bleeding, gastric ulcer $23(25.6 \%)$ was the most common attributable cause for the upper GI bleeding followed by oesophageal varices $14(15.6 \%)$; acute erosive/haemorrhagic gastropathy 11 (12.2\%); duodenal ulcer 9(10\%); growth 7(7.8\%); vascular lesions3(3.3\%); Mallory-weiss tear1 (1.1\%), and fundal varices $1(1.1 \%)$. In $21(23.3 \%)$ of cases no cause for bleeding was identified on endoscopic examination.

Oesophageal varices were most commonly found in Newar 7(29.2\%) and Mongolian 3 (18.8\%); and growth was found common in Newar 3(12.5\%), Aryans 3(6.5\%) and Mongolian 1(6.3\%). Gastric ulcer and duodenal ulcer were found most common cause of bleeding in Aryans $-17(37 \%)$ and 5(10.9\%) respectively. (Table 3)

Table 1: Age and Sex composition of the patients

\begin{tabular}{|l|c|c|c|}
\hline & Male & Female & Total \\
\cline { 2 - 4 } & No. $(\%)$ & No. $(\%)$ & No. (\%) \\
\hline $15-45$ & $26(44.8)$ & $21(65.6)$ & $47(52.2)$ \\
\hline $46-65$ & $21(36.2)$ & $9(28.1)$ & $30(33.3)$ \\
\hline 65 and above & $11(19.0)$ & $2(6.3)$ & $13(14.4)$ \\
\hline
\end{tabular}

Table 2: Clinical presentation of patients with Upper GI bleeding

\begin{tabular}{|l|c|}
\hline Clinical Presentation & No. (\%) \\
\hline Haematemesis & $51(56.7)$ \\
\hline Melaena & $13(14.4)$ \\
\hline Recent onset anemia with positive occult blood & $20(22.2)$ \\
\hline Haematemesis and melaena & $6(6.7)$ \\
\hline Total & $\mathbf{9 0}$ \\
\hline
\end{tabular}


Table 3: Relative frequency of causes of upper GI bleeding in different ethnic groups

\begin{tabular}{|l|c|c|c|c|c|c|}
\hline \multirow{2}{*}{ Aetiology } & Aryan & Mangolian & Newar & Dalit & Others & Total \\
\cline { 2 - 7 } & No. (\%) & No. (\%) & No. (\%) & No. (\%) & No. (\%) & No. (\%) \\
\hline Gastric ulcer & $17(37.0)$ & $2(12.5)$ & $4(16.7)$ & & & $23(25.6)$ \\
\hline Dudenal ulcer & $5(10.9)$ & $1(6.3)$ & $2(8.3)$ & $1(33.3)$ & & $9(10.0)$ \\
\hline Oesophageal varices & $3(6.5)$ & $3(18.8)$ & $7(29.2)$ & $1(33.3)$ & & $14(15.6)$ \\
\hline Fundal varices & $1(2.2)$ & & & & & $1(1.1)$ \\
\hline Growth & $3(6.5)$ & $1(6.3)$ & $3(12.5)$ & & & $7(7.8)$ \\
\hline $\begin{array}{l}\text { Acute Erosive/ Hemmorhagic } \\
\text { gastropathy }\end{array}$ & $4(8.7)$ & $4(25.0)$ & $3(12.5)$ & & & $11(12.2)$ \\
\hline Mallory weiss & & $1(6.3)$ & & & & $1(1.1)$ \\
\hline Vascular & $2(4.3)$ & & $1(4.2)$ & & & $3(3.3)$ \\
\hline Normal & $1(2.2)$ & & & & & $1(1.1)$ \\
\hline No cause identified & $10(21.7)$ & $4(25.0)$ & $4(16.7)$ & $1(33.3)$ & $1(100.0)$ & $20(22.2)$ \\
\hline Total & $\mathbf{4 6}$ & $\mathbf{1 6}$ & $\mathbf{2 4}$ & $\mathbf{3}$ & $\mathbf{1}$ & $\mathbf{9 0}$ \\
\hline
\end{tabular}

\section{Discussion}

Upper gastrointestinal haemorrhage is a prevalent and clinically significant condition with important implications for health care costs worldwide ${ }^{11}$. In the United kingdom, the overall incidence of acute upper GI haemorrhage is103 cases per 100,000 adults per year $^{12}$. In United States it is estimated to be 160 hospital admissions per 100,000 populations, which translates into more than 400,000 per year ${ }^{13}$. However, the incidence rate from most of the developing countries are largely unknown. In Nepal, there are only very few hospital-based published studies which have examined the incidence and clinical profile of upper GI bleeding.

Nepal is a country with inhabitant of diversely heterogeneous population. It has also a wide range of customs and cultural practices with different life-styles and health-related behaviours which may influence the development of a particular disease and might also predispose to cause of GI bleeding.

Ninty cases of upper GI bleeding were evaluated for the aetiology of upper GI bleeding in relation with different demographic profile. The males seemed predominantly affected more than females which is consistent with findings in other countries particularly US and UK. Although upper GI bleeding has been reported to be more common in elderly population most of our cases $(52.2 \%)$ are under 45 years of age. This disparity might be due to increased number of patients with oesophageal varices $(15.6 \%)$ as a result of alcoholic liver disease which commonly affect this age group.

The most common cause of upper GI bleeding was found to be peptic ulcer disease among which gastric ulcer was the commonest lesion followed by acute erosions and duodenal ulcer. This finding is not different from studies in other parts of the world which reports to vary from $19 \%$ to as high as $50 \%{ }^{14,15}$. The peptic ulcer has been shown most common in Aryans compared to other ethnic groups. Whereas the oesophageal variceal cause for bleeding is second most common (15\%) and appears to affect Newar and Mongolian ethnic groups more.

In one larger study from eastern Nepal by Bhattarai et $a$ found the similar pattern of frequency of causes of upper GI bleeding at different ethnic groups; and their mean age of presentation of GI bleeding was 49.6 years. In their study, oesophageal varices was found to be significantly higher in Mongolian origin; and this association was speculated to be due to higher frequency of alcohol consumption in this ethnic population ${ }^{16}$. Acute erosive gastropathy and GI growth had been found to be third and fourth causes ; and vascular cause for upper GI bleeding is found in 3 cases.

Adam et al in a similar study from Islamabad, found oesophageal variceal bleed most common aetiological diagnosis (44\%) followed by peptic ulcer disease (19.7\%). In $10.9 \%$ of cases the endoscopic finding was reported normal ${ }^{15}$. In our study, endoscopic examination could not reveal any cause for GI bleeding in as high as $22.2 \%$ of cases.

Limitations of our study are small sample size, retrospective descriptive type. The larger prospective study would help to verify or refute the findings in our study results.

In conclusion, upper GI bleeding is a common clinical problem and found commonly at middle age group people. Although peptic ulcer disease is still the most common cause of upper GI bleeding, oesophageal 
varices should be considered in certain ethnic groups as the specific management differs from other non-variceal cause of GI bleeding.

\section{References}

1. Loren L. Gastrointestinal bleeding. In: Braunwald E, Fauci AS, Dasper DL, Hauser SL, Longo DL, Jameson JL (editors). Harrison's Principle of Internal medicine. USA: McGrawHill Companies Inc; 2005.p.235.

2. Silverstein FE, Gilbert DA, Tedesco FJ et al. The national ASGE survey on upper gastrointestinal bleeding. I. Study design and baseline data. Gastrointestinal Endoscopy. 1981:27:73-9.

3. Larson DE, Farnell MB. Upper gatrointestinal hemorrhage. Mayo clin proc. 1983:58:371-87.

4. Palmer ED. Upper gastrointestinal haemorrhage. JAMA. 1975:231:853-5.

5. Fallah MA, Prakash C, Edmundowicz S. Acute gastrointestinal bleeding. Med Clin North Am. 2000:84(5):1183-208.

6. Kandarpa K, Aruny JE. Acute gastrintestinal bleeding. In: Handbook of interventional Radiologic Procedures. 2nd ed. USA: Lippincott Williams \& Wilkins; 1996.p.130-8.

7. da Silveira EB, Lam E, Martel M, Bensoussan $\mathrm{K}$, Barkun AN. The importance of process issues as predictors of time to endoscopy in patients with acute upper-GI bleeding using the RUGBE data. Gastrointestinal Endosc. 2006:64(3):299309.

8. Spiegel BM, Vakil NB,Ofman JJ. Endoscopy for acute nonvariceal upper gastrointestinal tract haemorrhage: is sooner better? A systematic review. Arch Intern Med. 2001:161(11):1393404.

9. Lee JG, Turnipseed S, Romano PS, Vigil H, Azari R, Melnikoff N, et al. Endoscopy- based triage significantly reduces hospitalization rates and costs of treating upper GI bleeding: a randomized controlled trial. Gastrointest Endosc. 1999:50(6):755-61.

10. Axon AT, Bell GD, Jones RH, Quine MA, McCloy RF. Guidelines on appropriate indications for upper gastrointestinal endoscopy. Working Party of the joint Committee of the Royal College of Physicians of London, Royal College of Surgeons of England, Royal College of Anaesthetics, Association of surgeons, British Society of Gastroenterolgy, and the Thoracic Society of Great Britain. BMJ. 1995:310(6983):853-6.

11. Ian M, Gralne, MD, Barkun AN, C.M., Bardou M. Management of Acute Bleeding from a Peptic Ulcer. NEJM. 2008: 359(9):928-37.

12. Rockall TA, Logan RF, Devlin HB. Incidence of and mortality from acute upper gastrointestinal haemorrhage in the United Kingdom. Steering Committee and members of the National Audit of Acute Upper Gastrointestinal Haemorrhage. BMJ. 1995:311(6999):222-6.

13. Lewis JD, Bilker WB, Brensinger C, Farrar JT, Strom BL. Hospitalization and mortality rates from peptic ulcer disease and GI bleeding in the 1990s: relationship to sales of nonsteroidal anti-inflammatory drugs and acid suppression medications. Am J Gastroenterol. 2002:97:254049.

14. Loren Laine, Walter L. Peterson. Bleeding Peptic Ulcer. NEJM. 1994;331:717-

15. Adam T, Jayid F, Khan S. Upper gastrointestinal bleeding: An etiological study of 552 cases. J Pak Inst Med Sci. 2004:15(1):845-8.

16. Bhattarai J, Acharya P, Barun B, Pokhrel S, Uprety N, Shrestha NK. Comparison of endoscopic findings in patients from different ethnic groups undergoing endoscopy for upper gastrointestinal bleed in Eastern Nepal. NMCJ. 2007; 9. 